Table 1 Mean and Range of monitored concentrations of BaP.

(unit:ng/m $\mathrm{m}^{3}$ )

\begin{tabular}{|c|c|c|c|c|c|c|c|}
\hline \multirow[b]{2}{*}{ Sample No } & \multirow[t]{2}{*}{ Total } & \multicolumn{2}{|c|}{ Season } & \multirow{2}{*}{$\begin{array}{l}\text { Distance } \\
\text { road side }\end{array}$} & \multirow{2}{*}{$\begin{array}{r}\text { from road } \\
20 \sim 500 \mathrm{~m}\end{array}$} & \multicolumn{2}{|c|}{ Space } \\
\hline & & Winter & Spring Fal1 & & & Indoor & Outdoor \\
\hline 1 & $\begin{array}{r}2.88(n=6)^{72} \\
(0.24 \sim 9.17)\end{array}$ & $(1.04 \div 9.05$ & $(0.24 \div 6.41)$ & - & $(0.24 \sim 98.17)$ & - & $(0.24 \sim 98.17)$ \\
\hline 2 & $\begin{array}{l}0.64(n=3) \\
(0.53 \sim 0.70)\end{array}$ & - & $(0.53 \sim 0.64$ & - & $\begin{array}{c}0.64 \\
(0.53 \sim 0.70) \\
\end{array}$ & - & $\begin{array}{c}0.64 \\
(0.53 \sim 0.70) \\
\end{array}$ \\
\hline 3 & $\begin{array}{l}5.37(n=43) \\
(0.35 \sim 15.09)\end{array}$ & $(0.5 \stackrel{6.48}{\sim} 15.09)$ & $(0.35 \sim 48$ & $(1.51 \sim 15.09)$ & ) $(0.35 \div 18$ & $(0.7 .02 \sim 4.59$ & 9) $(0.35 \div 375.09)$ \\
\hline 4 & $\begin{array}{l}2.18(n=2) \\
(0.29 \sim 21.0)\end{array}$ & - & - & - & $(0.29 .18$ & - & $\left(0.29^{2.18} \sim 21.0\right)$ \\
\hline 5 & $\begin{array}{l}1.20(n=17) \\
(0.17 \sim 2.50)\end{array}$ & $\begin{array}{c}2.20 \\
(1.6 \sim 2.5)\end{array}$ & $\begin{array}{c}0.89 \\
(0.17 \sim 2.2) \\
\end{array}$ & - & $(0.17 \sim 2.5)$ & $(0.27 \sim 1.74$ & 4) $\left(0.1 \frac{1}{7.20} \sim 2.5\right)$ \\
\hline 6 & $\begin{array}{l}1.85(n=24) \\
(0.09 \sim 7.70)\end{array}$ & $\begin{array}{c}2.49 \\
(0.19 \sim 6.8)\end{array}$ & $(0.09 \sim 7.7)$ & $(2.2 .15$ & $(0.08 \sim 10.38)$ & $\begin{array}{r}2.16 \\
(0.28 \sim 6.45 \\
\end{array}$ & 5) $(0.0927 .7)$ \\
\hline 7 & $\begin{array}{l}1.27(n=10) \\
(0.40 \sim 2.95)\end{array}$ & $\left(0 . \frac{1.26}{2} \sim 2.95\right)$ & $\left(0 . \frac{1.28}{4} \sim 2.05\right)$ & $(0.4 \sim 27.95)$ & - & - & $(0.4 \sim 2.95)$ \\
\hline 8 & $\begin{array}{l}1.16(n=13) \\
(N D \sim 3.36)\end{array}$ & $(0.29 \sim 2.92)$ & $\begin{array}{l}1.15 \\
(\mathrm{ND} \sim 3.36)\end{array}$ & - & $\begin{array}{l}1.16 \\
(N D \sim 3.36)\end{array}$ & - & $\begin{array}{c}1.16 \\
(N D \sim 3.36) \\
\end{array}$ \\
\hline 9 & $\begin{array}{l}1.55(n=9) \\
(0.1 \sim 7.05)\end{array}$ & - & - & - & $(0.1 \sim 75$ & - & $(0.1 \sim 7.05)$ \\
\hline 10 & $\begin{array}{c}1.19(n=10) \\
(0.01 \sim 9.65)\end{array}$ & $\stackrel{1.58}{(1.05 \sim 2.35)}$ & $(0.42 \sim 1.4)$ & - & - & - & $\left(0.011^{1.19} \sim 9.65\right)$ \\
\hline
\end{tabular}

*a: $n$ is No. of data

どにより大きく変動する。表中のデータは1981年以後の大都市(11の政令都市と東京都(23区部))の国設大気 污染観測所、各道都府県市の環境関連研究所及び学会発表のデータを整理した值である。Sample No. は各市 を表し、各市のデータは入手できた資料のデータだけを用いたので、必ずしすすべてのデータを網羅しては いない。また、観測值の変動要因としても表であげた要因以外にも観測地点の気象環境、空気と粉塵の採集 方法、分析方法、周辺環境などの他の要因む充分考えられるがデータの制約上、今回の検討からは除いた。

\title{
2.2 リスク評価のシナリオ
}

一般的に、発ガン性物質と非発ガン性物質に分け、リスク評価方法が区別されている。BaPは強い発ガン 性物質なので閾值のないリスク推定とし、図ー1のフローチャートに沿ってリスク評価を行う。環境中濃度 を観湘值またはモデル值を用い大気中の BaPの濃度を推定する。量一反応関係は動物実験の結果による発ガ ンデータを用い、暴量評価では呼吸量 $\left(20 \mathrm{~m}^{3} / \mathrm{d}\right)$ 、暴露時間、暴露空間などから空気からの摂取量を推定する。 さらに暴露レベル(総摂取量)をマルチステージモデルから求めたVSD(Virtually Safe Dose)と比較し、リス クレベルを求める。

\section{BaPの濃度推测モデル}

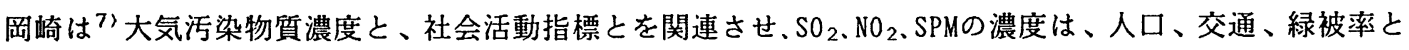

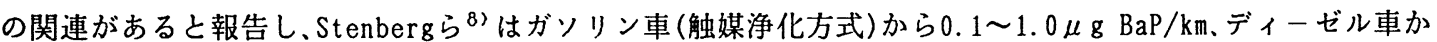

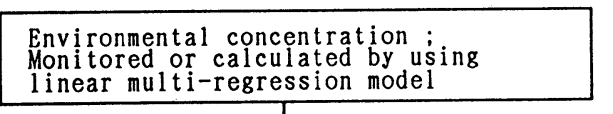

Dose-response relationship ; Determine an appropriate tumor incidence model

arposure

Exposure Analysis:

Exposure estimation, inhalation $\left(20 \mathrm{~m}^{3} / \mathrm{d}\right)$

Comparing process;

Exposure level. VSD (Virtually Safe Dose)

Risk characteristics :

Risk level, sensitivity analysis

Fig. $1 \mathrm{Risk}$ assessment process of $\mathrm{BaP}$
らは1〜10 $\mu \mathrm{gBaP} / \mathrm{km}$ の排出量を報告し、泉川ら ${ }^{9 / 10)}$ はガソリ ン自動車から0.01〜1.74 $\mu \mathrm{g} \mathrm{BaP} / \mathrm{km}$ 、ディーゼル自動車から $1 \sim 11.7 \mu \mathrm{g} \mathrm{BaP} / \mathrm{km}$ を報告し、いずれもディーゼル自動車から

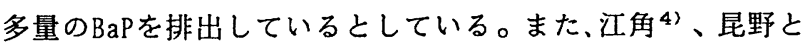
江角 ${ }^{3)}$ はSPM濃度、オキシダント濃度、気温を説明変数とする 線形重回帰式を作成し、その適合度を報告している。

本研究では、モデルとして都市活動指標を説明変数として 用いるマクロ回帰モデル式と、自動車交通量、浮遊粉塵を説 明変数として用いるミクロ回帰モデルに分けて、都市大気中 のBaP濃度を推測する。

3.1 マクロ回帰モデル式の設定および検定

大都市の BaPによる健康リスクを評価するために表一 2 の 
Table 2 Urban activities of ten major cities.

\begin{tabular}{ccccccc}
\hline $\begin{array}{c}\text { City } \\
\text { No. }\end{array}$ & $\begin{array}{c}\text { City area } \\
\left(\mathrm{km}^{2}\right)\end{array}$ & $\begin{array}{c}\text { Urbanized } \\
\text { area }\left(\mathrm{km}^{2}\right)\end{array}$ & $\begin{array}{c}\text { Road area } \\
\left(\mathrm{km}^{2}\right)\end{array}$ & $\begin{array}{c}\text { Paved rqad } \\
\text { area }\left(\mathrm{km}^{2}\right)\end{array}$ & $\begin{array}{c}\text { No. of car } \\
(1000 \mathrm{cars})\end{array}$ & $\begin{array}{c}\mathrm{BaP} \\
\left(\mathrm{ng} / \mathrm{m}^{3}\right)\end{array}$ \\
\hline 1 & 1118.01 & 235.500 & 41.975 & 21.626 & 491.299 & 4.05 \\
& 1119.07 & 236.900 & 45.426 & 26.926 & 567.969 & 2.10 \\
\hline 2 & 788.05 & 170.430 & 18.112 & 17.352 & 414.415 & 0.64 \\
\hline 3 & 597.08 & 565.530 & 87.126 & 86.180 & 2475.142 & 6.48 \\
& 600.77 & 565.530 & 88.580 & 87.820 & 2653.042 & 2.58 \\
\hline 4 & 142.21 & 125.430 & 12.960 & 11.284 & 258.081 & 2.18 \\
\hline 5 & 429.62 & 325.360 & 41.864 & 33.454 & 769.159 & 2.20 \\
& 430.11 & 325.470 & 43.417 & 36.846 & 871.219 & 0.89 \\
\hline 6 & 327.07 & 301.340 & 50.515 & 48.808 & 1019.816 & 2.49 \\
& 327.14 & 301.340 & 49.926 & 48.695 & 1010.906 & 1.47 \\
\hline 7 & 216.00 & 204.500 & 37.758 & 36.288 & 856.850 & 1.26 \\
& 216.00 & 204.500 & 37.758 & 36.288 & 856.850 & 1.28 \\
\hline 8 & 543.57 & 197.98 & 23.326 & 20.020 & 349.886 & 1.18 \\
& 543.78 & 197.98 & 23.806 & 20.723 & 411.814 & 1.15 \\
\hline 9 & 696.49 & 139.590 & 17.575 & 16.318 & 358.367 & 1.55 \\
\hline 10 & 479.88 & 186.88 & 23.000 & 21.506 & 367.506 & 1.58 \\
& 479.88 & 186.88 & 23.000 & 21.506 & 367.506 & 1.03 \\
\hline
\end{tabular}

* Upper and lower part mean data of winter and other seasons.
ような、都市活動指標を説明変 数とするマクロ線形重回帰モデ ルを開発した。表のデータ中、 都市活動データは11の政令都市 と東京都（区都）を合わせ12大 都市の中で1981年以後の BaPの 観測值が入手できた都市を対象 とし、大都市比較統計年表の 19 81年以後のデータを BaPの観測 值がある年のデータだけを算術 平均したもので、BaPの值は12大 都市の1981年以後の観測デー夕 で、1990年度の「化学物質と環 境」のデータの他、各道都府県 市の公害センター、環境研究所、 学会などの資料を入手し、算術

平均して、用いた。BaP濃度は移動発生源である自動車排出ガスに大きく左右される。BaP濃度は冬期(12月 〜2月)に高く、夏期に低い結果が観測さらていて、本論文では冬とそれ以外の季節に区分してモデルを検討 した。表一 2 の基礎データを市域面積当たりの道路面積、市域面積当たりの市域内自動車保有台数などのよ うに加工し、相関係数を作成し、目的変数との相関が高い変数の中で、内部相関が強い変数では片方を取り 去るなどとして、残差の検討、分散分析などの統計的処理に加え、物理的現象としての整合性の確認を行い、 次式のような結果を得た。

$$
\begin{aligned}
& \mathrm{C}_{\mathrm{BaP} 1}=-6.850-0.142 \cdot \mathrm{R}_{\mathrm{RC}}+0.496 \cdot \mathrm{R}_{\mathrm{CP}} 、(\mathrm{R}: 0.85 、 \mathrm{p}<0.05) \\
& \mathrm{C}_{\mathrm{BaP} 2}=-0.668-0.268 \cdot \mathrm{R}_{\mathrm{RC}}+0.175 \cdot \mathrm{R}_{\mathrm{RU}}+0.968 \cdot \mathrm{R}_{\mathrm{CC}} 、(\mathrm{R}: 0.89, \mathrm{p}<0.05)
\end{aligned}
$$

ここで、 $C_{\mathrm{BaP} 1 、} \mathrm{C}_{\mathrm{BaP} 2}$ は冬期とそれ以外の季節の $\mathrm{Bap}$ の予測濃度 $\left(\mathrm{ng} / \mathrm{m}^{-3}\right) 、 \mathrm{R}_{\mathrm{R}}$ は市域面積に対する市内道路 面積の割合 $(\%) 、 R_{\mathrm{CP}}$ は市域内舗装道路面積に対する市内の自動車の保有台数の割合 $\left(1000\right.$ 台 $\left./ \mathrm{Km}^{2}\right) 、 \mathrm{R}_{\mathrm{RU}}$ は市街 化区域面積に対する市内道路面積の割合 $(\%) 、 R_{\mathrm{Cc}}$ は市域面積に対する市内の自動車の保有台数の割合 (1000 台 $\left./ \mathrm{km}^{2}\right)$ である。Rは重相関係数を示す。

\section{2 ミクロ回帰モデル式の設定および検定}

前節のマクロモデルは都市活動指標だけで濃度推測が可能で、大都市全体レベルの大まかなリスクを評価 するのに有用であるが、市域内のある特定の地域、例えば、道路沿いの大気中での濃度の推測はできない。 そこで、この節では、地域環境特性に基づいたミクロ線形重回帰モデルを開発し、リスク変動の幅を評する ことを試みる。

大気中 $\mathrm{BaP}$ の濃度に直接に影響を与える因子としては、浮遊粉塵粒子が知られており、また地域環境特性 としては、自動車交通量、道路からの距離、大型車混入率などの因子が注目されてきた。そこで、本研究で は、SPMの代わりに浮遊粉塺 (SP)、自動車交通量、道路からの距離、大型車混入率などを説明变数とするミ クロ重回帰モデルを設定する。

道路周辺地域での BaPの濃度は、道路に近い程一般的に濃度が高く観测され、自動車排気ガスの影響を受 けている。モデル設定に用いるデータは1981年以後の公表データ中、BaP濃度、浮遊粉塵濃度、自動車交通 量、大型車混入率が記入されているデータを観測地域ごとに再整理し、接道上の測定值と道路端から20〜500 m位離れた地域での観测值に分け、マクロモデルの場合と同様、回帰分析を行い、線形重回帰モデルを得た。

$$
\begin{aligned}
& \mathrm{C}_{\mathrm{BaP} 3}=-0.253+0.016 \cdot \mathrm{P}+0.020 \cdot \mathrm{T} 、 \quad(\mathrm{R}: 0.84 、 \mathrm{p}<0.01) \\
& \mathrm{C}_{\mathrm{BaP} 4}=-3.843+0.044 \cdot \mathrm{P}+0.036 \cdot \mathrm{T} 、 \quad(\mathrm{R}: 0.96 、 \mathrm{p}<0.01)
\end{aligned}
$$

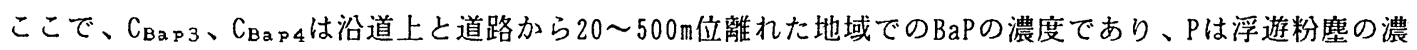
度 $\left(\mu \mathrm{g} / \mathrm{m}^{3}\right) 、 T$ は交通量 $(1000$ 台 $/ 12 \mathrm{hrs})$ である。図ー2 に実測值と計算值との関係を示す。サンプル番号は 


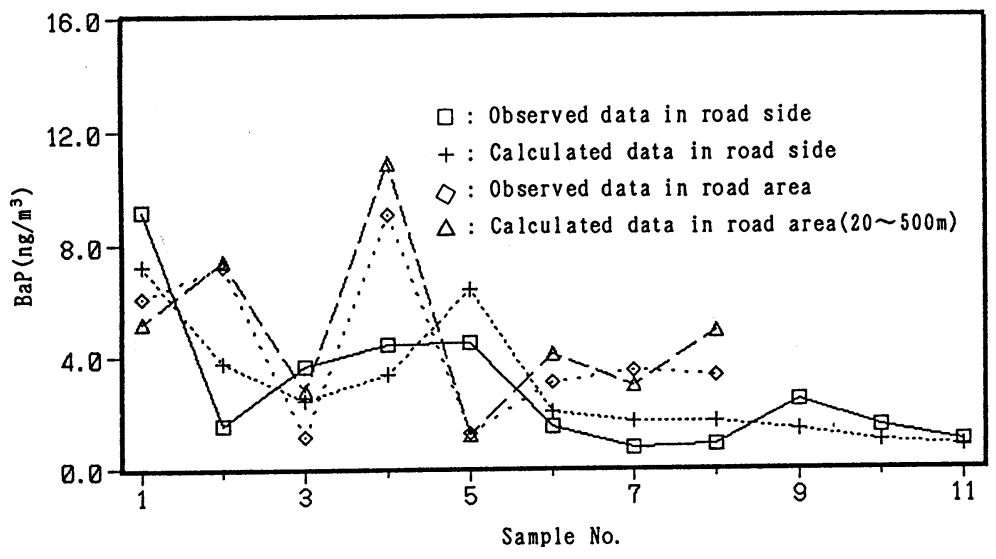

Fig. 2 Observed and Calculated concentrations of BaP in Road area
両地域の実測值と予測値の関 係を示すだけで、両地域の同 一観測地点ではない。

\section{4. 経気リスク評価}

\subsection{BaPの発ガン毒性} $\mathrm{BaP}$ は極めて強い発ガン性 を持つ物質で、ラット、マウ ス、ヘムスター、モルムット、 ウサギ、サル、そのほか計9 種類の動物すべてに、かつ経 口、経皮、吸入すべての投与 経路で、発ガン性を示すこと が知られている。Carnowら ${ }^{11)}$

によれば、BaPの濃度が $1 \mu \mathrm{g} / 1000 \mathrm{~m}^{3}$ 増加することにより呼吸器関連ガン死亡率は5\%増加すると報告してお り、Hitosugi ${ }^{12)}$ む BaPとの関連を認めている。U.S. EPA ${ }^{13)}$ は七ト発ガン性についての総合的な証拠の重み の類別で動物実験からの十分な証拠と、七トの疫学調查からの不十分なデータから B-2に分類し、経口と吸 入による発ガン能(Carcinogenic potency)を線形マルチステージ法にもとづいて算定し、各々 $11.53(\mathrm{mg} / \mathrm{kg}$ $/ \mathrm{d})^{-1}$ と $6.1(\mathrm{mg} / \mathrm{kg} / \mathrm{d})^{-1}$ を利用している。また、Shabad ${ }^{14)}$ はBaPに対する量一反応の関係に基づいてMAC(最 大許容濃度)として $0.1 \mu \mathrm{g} / 100 \mathrm{~m}^{3}$ を提案している。

\section{2 標準都市の設定およびその大気中の BaP濃度の予測}

大都市での BaPによる人体の健康へのリスクは都市活動指標と関連があることが、前章の重回帰分析の結 果から推察される。本論文では、日本の大都市の平均的なリスク水準を評価し、リスク評価に与える観測值 の変動要因を検討する標準都市を設定する。表ー 3 に標準都市の規模および都市活動指標を示す。表のデー 夕は1989年度の11政令都市と東京都 (区都)の資料を算術平均した值である。マクロ回帰モデルを用いて標準 都市大気中のBaPの濃度を予測した。冬期が平均濃度 $3.81\left(\mathrm{ng} / \mathrm{m}^{3}\right)$ 、範囲 $1.00 \sim 6.82\left(\mathrm{ng} / \mathrm{m}^{3}\right)$ 、その以外の時 期で平均 $1.68\left(\mathrm{ng} / \mathrm{m}_{3}\right) 、$ 範囲1.09〜3.08 $\left(\mathrm{ng} / \mathrm{m}^{3}\right)$ の濃度になった。

\section{3 人の健康へのリスク評価}

\section{(1) 経気曝露量推定}

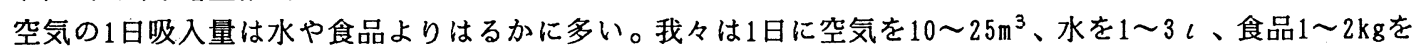
䀧取している。中川ら ${ }^{15)}$ は食事、空気、飲用水からの BaPの摂取量を横浜市在住の成人女性を対象に行い、 空気からは夏期 25 35ng、冬期90〜118ngを報告し、しかす、交通量の多い幹線道路に面した家庭の居住者 のPAHsの 1 日摄取量は他の対象者より約2〜3倍高いとしている。ところで、1 日のうち日常生活の大部分は 室内環境での生活である。松下ら ${ }^{16)}$ は東京およびその近郊に住む人々の各種生活空間における平均滞在時間

Table 3 Urban activities of standardized city.

\begin{tabular}{|c|c|c|c|}
\hline Parameters & Mean & Min. & Max. \\
\hline \multirow{6}{*}{$\begin{array}{l}\text { City area }\left(\mathrm{km}^{2}\right) \\
\text { Urbanized area }\left(\mathrm{km}^{2}\right) \\
\text { Road area }\left(\mathrm{km}^{2}\right) \\
\text { Paved road }\left(\mathrm{km}^{2}\right) \\
\text { No. of car } \\
\text { (1000 cars) } \\
\text { Road area/ } \\
\text { City area }(\%) \\
\text { Road area/ } \\
\text { Urbanized area }(\%) \\
\text { No. of car } / \mathrm{City} \\
\left.\text { area(1000cars } / \mathrm{km}^{2}\right) \\
\text { No. of car/ } \\
\text { Paved road area } \\
\left(1000 \mathrm{cars} / \mathrm{km}^{2}\right)\end{array}$} & $\begin{array}{r}530.046 \\
230.316 \\
35.966 \\
33.503\end{array}$ & $\begin{array}{r}142.770 \\
125.900 \\
14.480 \\
14.046\end{array}$ & $\begin{array}{r}1121.180 \\
568.120 \\
90.408 \\
89.815\end{array}$ \\
\hline & 839.735 & 373.926 & 2921.275 \\
\hline & 8.308 & 2. 298 & 17.352 \\
\hline & 15.254 & 10.627 & 21.819 \\
\hline & 1.968 & 0.526 & 4.730 \\
\hline & 23.872 & 16.493 & 32.530 \\
\hline
\end{tabular}

を調查した結果、サラリーマン室内滞在時間は20. $9 \sim 21.3$ (平均 21.1) 時間、主婦 $21.6 \sim 22.3$ (平均 21.9)時間、戸外にいる時間はわずかにサラリーマ ンで0. 9〜 1.2(平均1.1) 時間、主婦で1.4〜1.9(平 均1.8)時間に過ぎないとしている。そこで、本研 究では、経気吸入曝露環境として空気だけを想定 し、曝露時間として室内 21.5 時間、戸外時間は移 動時間む含め、2.5時間と見なし、曝露量を推定す る。室内濃度については三谷ら ${ }^{17)}$ の外気の濃度と の相関分析からの相関式を用いて推定する。表一 4 に標準都市での呼吸による Bapの暴露量の推定 
Table 4 lluman exposure analysis of BaP in standardized city.

\begin{tabular}{|c|c|c|c|c|c|c|}
\hline & \multicolumn{3}{|c|}{ Winter } & \multicolumn{3}{|c|}{ Spring Fall } \\
\hline & Total & Indoor & Outdoor & Total & Indoor & Outdoor \\
\hline $\begin{array}{l}\text { Exposure time }(\mathrm{hr}) \\
\text { Estimated conc. }\left(\mathrm{ng} / \mathrm{m}^{3}\right)\end{array}$ & 24.0 & $\begin{array}{l}21.5 \\
2.82\end{array}$ & $\begin{array}{l}2.50 \\
3.81\end{array}$ & 24.0 & $\begin{array}{l}21.5 \\
1.50\end{array}$ & $\begin{array}{l}2.50 \\
1.68\end{array}$ \\
\hline $\begin{array}{l}\text { Exposure through } \\
\text { inhalation }(\mathrm{ng} / 60 \mathrm{~kg} / \mathrm{d})\end{array}$ & 58.47 & 50.63 & 7.94 & 30.38 & 26.88 & 3.50 \\
\hline
\end{tabular}

結果を示す。これらの結

* $\mathrm{C}_{\text {Bap }}$ iw $=0.53 \cdot \mathrm{C}_{\mathrm{Ba}}$ POw+0.8 $(\eta=32, r=0.88, \mathrm{p}<0.001)$

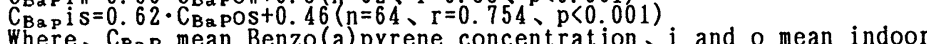
and outdoor, w and $s$ mean winter and other seasons.

果は米国のPhillipsburg で行われた経気吸入量の $78 \sim 385(\mathrm{ng} / \mathrm{d})^{18)}$ と松下 と田辺 ${ }^{19)}$ の個人サンプ ラーを用いた結果の 21.8 〜 32.2 (ng/d) (著者推定) と同じオーダである。

（2）人の健康への経気りスク評価

呼吸器関連ガンに対する発ガン性については、動物実験の結果から BaPの呼吸器内および肺内注入などに より量一反応関係 ${ }^{20>-22)}$ が認められている。しかし、一般環境におけると同じような低い容量レべルでの反 応率は、動物実験によっても疫学調查によっても直接には観測できないので、得られたデータをもとに低濃 度領域まで外挿する必要がある。低容量の外挿には多数の数学モデルがあるが、本研究では現在のところ米 国で良く利用されているマルチステージモデルを用いる。

$$
P(D)=1-\exp \left(-\sum_{i=0}^{n} q_{i} \cdot D^{1}\right)
$$

ここで、P (D) は各化学物質の投与量がDの時の発がん確率、qは発がんデータから求められる定数である。 本研究では、石西ら ${ }^{21)}$ のラットを使用してBaP混濁液を肺内に直接注入し得た結果に基づき、1 $0^{-6}$ 生涯リス クに対するVSDを算定し、前節で推定した暴露量に対する経気りスクを計算した。表ー 5 にVSDの推定結果と

Table 5 Estimated VSD and Risk Levels of BaP.

\begin{tabular}{|c|c|c|c|c|}
\hline \multirow{2}{*}{\multicolumn{2}{|c|}{ VSD for $10^{-6}$ lifetime risk }} & \multicolumn{2}{|c|}{$\begin{array}{l}\operatorname{VSD}(\mathrm{mg} / \mathrm{kg} / \mathrm{d}) \\
\text { Multistage One-hit }\end{array}$} & $\begin{array}{l}\text { U. } \\
q_{1} * \text { S. } \\
\text { (mg } / \mathrm{kg} / \mathrm{d})^{-1}\end{array}$ \\
\hline & & $2.728 \times 10^{-7}$ & $2.45 \times 10^{-7}$ & $6.11^{\times a}$ \\
\hline $\begin{array}{l}\text { Ratio to VSD for } 10^{-6} \\
\text { lifetime cancer }\end{array}$ & $\begin{array}{c}\text { Winter } \\
\text { Spring } \sim \text { Fall }\end{array}$ & $\begin{array}{ll} & 3.57 \\
1 & 1.86\end{array}$ & $\begin{array}{l}3.97 \\
2.06\end{array}$ & $\begin{array}{l}\text { 5. } 95 \times 10^{-6} \times b \\
\text { 3. } 09 \times 10^{-6} \times b\end{array}$ \\
\hline
\end{tabular}

*a: $q_{1}{ }^{*}$ (individual excess 1 ifetime cancer risk rate from inhalation),

*b: excess cancer from inhalation $\left(\mathrm{q}_{1}{ }^{*} \times \mathrm{D}(\mathrm{mg} / \mathrm{kg} / \mathrm{d})\right)$

発ガンリスクは10-6のオーダになる。
経気リスクの推定結果を、 ワン・ヒットモデルとU. S.EPAの方法で推定した 結果と一緒に示す. $10^{-6}$ 生涯リスクの VSDに対す る比は1.86〜3.57で、経 気吸入による呼吸器関連

\section{5 ．経気リスク評価に与える大気中BaP濃度の変動要因の分析}

観測值は観測時の季節、気象要因、都市活動指標、場所などの条件により変動が大きく、その解积ににあ たってはこれらの諸要因を考虑する必要性がある。そこで、本研究ではマクロ回帰モデルを用い、都市活動 関連指標、季節などがリスク評価に与える影響の評価、ミク口回帰モデルを用い、交通量、道路からの距離 などの要因がリスク評価に与える影響を感度分析を通じて評価し、観測時の考慮事項として検討してみた。 表 -6 に感度解析の結果を示す。表の中の数字は各モデルのパラメータの值を実在のデータから求めた変動 の幅を与えたときの BaPの推定濃度及び経気りスクの变動の程度を表す。マクロ回帰モデルの分析は表 -4 の結果をむとに、ミクロ回帰モデルの解析はモデル開発の時に用いたデータの変動の幅を与えた。さらに、 Table 6 Sensitivity analysis of BaP concentration.

\begin{tabular}{|c|c|c|c|c|c|c|c|c|c|c|c|c|c|c|c|c|c|c|}
\hline & \multicolumn{4}{|c|}{ Winter } & \multicolumn{6}{|c|}{ Spring Fall } & \multicolumn{4}{|c|}{ Road side $(0 \mathrm{~m})$} & \multicolumn{4}{|c|}{ Road area $(20 \sim 500 \mathrm{~m})$} \\
\hline & \multicolumn{2}{|c|}{$\begin{array}{l}\text { Poad area/ } \\
\text { city area(\%) }\end{array}$} & \multicolumn{2}{|c|}{$\begin{array}{l}\text { No. of car/Paved road } \\
\text { area }\left(1000 \text { cars } / \mathrm{km}_{2}\right)\end{array}$} & \multicolumn{2}{|c|}{$\begin{array}{l}\text { Road area/ } \\
\text { city area (\%) }\end{array}$} & \multicolumn{2}{|c|}{$\begin{array}{c}\text { Road area/Nrba- } \\
\text { nized area }(\%)\end{array}$} & \multicolumn{2}{|c|}{$\begin{array}{l}\text { No. of car/City } \\
\text { area }\left(1000 \mathrm{cars} / \mathrm{km}^{2}\right)\end{array}$} & \multicolumn{2}{|c|}{$\mathrm{SP}(\mathrm{ug} / \mathrm{m} 3)$} & \multicolumn{2}{|c|}{$\begin{array}{c}\text { Traffic } \\
(1000 \text { cars } / 122\end{array}$} & \multicolumn{2}{|c|}{$\underset{\mathrm{SP})}{\mathrm{SP} \text { (ug/m3) }}$} & \multicolumn{2}{|c|}{$\begin{array}{c}\text { Traffic } \\
(1000 \text { cars } / 12 \mathrm{hrs})\end{array}$} \\
\hline & 0.25 & 2.0 & 0.7 & 1.4 & 0.25 & 2.0 & 0.7 & 1.5 & 0.25 & 2.4 & 0.3 & 2.7 & 0.23 & 2.4 & 0.5 & 2.1 & 0.5 & 2.3 \\
\hline $\begin{array}{l}\text { BaP conc. } \\
\left.\text { (ng/m } \mathrm{m}^{3}\right)\end{array}$ & 2 & 2 & 5 & 6 & 5 & 6 & 3 & 4 & 5 & 6 & 3 & 6 & 2 & 3 & 4 & 6 & 2 & 4 \\
\hline $\begin{array}{l}\text { Ratio to VSD } \\
\text { for } 10^{-6} \text { risk }\end{array}$ & 1 & 2 & 4 & 5 & 4 & 5 & 2 & 3 & 4 & 6 & 2 & 5 & 1 & 2 & 3 & 6 & 1 & 3 \\
\hline
\end{tabular}

* Evaluation of variation range resulted from parameter setting; $0 \sim 20: 1,20 \sim 40: 2 、 40 \sim 60: 3,60 \sim 80: 4,80 \sim 100: 5,100 \sim: 6$ 
ミクロ回帰モデルからの $\mathrm{BaP}$ 屋内濃度の推定は、安藤と田村 ${ }^{231}$ の東京都内幹線道路周辺の推定モデル式を 用いた。マクロ回帰モデルの感度解析結果からは舗装道路面積と市内面積に対する市内自動車保有台数の割 合が60\% 100\%以上の変動を示している。ミクロ回帰モデルの解析結果は大気中BaP濃度との相関が知られて いる浮遊粉塺の濃度の影響が $20 \%$ から100\%以上の変動を表す。経気リスクに対する影響も各要因の変動によ り〜100\%まで変動することがわかる。これらの結果から観测の時は都市活動指標、道路環境特性などを考慮 することの重要性が推察された。

\section{6. 結論}

大気中のベンゾ( $(a)$ ピレンの経気リスクを推定し、リスク評価に与える観測值の変動要因の評価を行い、得 られた成果を以下にまとめる。

(1) 都市大気中のBaPの濃度を推定する目的で、都市活動指標を用いるマクロ回帰モデルと沿道環境特性を考 慮したミクロ回帰モデルを開発し、有用性を確認した。

(2) BaPの人への健康リスク評価を行い、標準都市でのリスクレベルは生涯経気リスクで10-6レベルであった。 (3)経気りスク評価に与える大気中のBaP濃度の変動要因を分析する目的で、実在のデータから求めた值の変 動幅を線形重回帰モデルを用いて感度分析を行った。都市活動指標を用いるマクロ回帰モデルでは舗装道路 面積と市域面積に対する市内自動車保有台数の割合が、ミクロ回帰モデルでは浮遊粉塵濃度の影響が大きい と解釈され、観測の時には都市活動指標、道路環境などを考慮することの重要性が明らかになった。

なお、本研究を進めるに当たり、有益なコメントを戴いた大阪大学環境工学科の城戸由能助手、大気污染 の基礎的なデータの収集で世話になった大阪市環境科学研究所の栘元慶子氏に深く感謝いたします。

\section{7 . 参考文献}

1) Waller、R.E. ; Brit. J. Cancer、Vol. 8、pp. 8 21、1952

2) Butler、J.D. and P. Crossley; Environmental Pollution、Vol. 3、p. 109、1982

3）屁野 信也、江角 光典; 埼玉県公害センター年報、Vol. 14、pp. 32〜 40、1987

4) 江角 光典; 埼玉県公害センター年報、Vol. 12、pp. 30〜37、1985

5) 風谷 奎一; 大気污染学会誌、Vol. 26(1)、pp. 23〜28、1991

6) Sawicki E. et al. ; Am. Ind. Hyb. Assoc. J. 、Vol. 23(2)、pp. 137 144、1962

7) 岡崎. 淳 ; 千葉県公害研究所研究報告、Vol. 22(1)、pp. 9 24、1990

8) Stenberg、U. et al. ; Environmental Health Perspectives、Vol. 47、pp. 53 63、1983

9) 泉川蹟雄ら; 東京都環境科学研究所年報告、pp. 24 35、1989

10)泉川蹟雄ら; 東京都環境科学研究所年報告、pp. 3 10、1990

11)Carnow、B.W. and Meier、P. ; Archives of Environmental Health、Vol. 27、pp. 207 219、1973

12) Hi tosugi 、M. ; 公衆衛生院研究報告、Vol. 17、pp. 237 256、1968

13) U.S. EPA ; Pb-Rep、EPA/540/1-86/022、pp. 1 31、1984

14) Shabad 、. M. ; Neoplasma 、Vol. 22、pp. 459 468、1975

15) 中川 友夫ら; 横浜衛生年報、Vol. 30、pp. 113 116、1991

16)松下 秀鶴、田辺 潔; 「人間環境系」研究報告集 G03P - N30、pp. 392 393、1990

17) 三谷 一憲; 衛生化学、Vol. 36(5)、pp. 449 454、1990

18) Lioy、P. L. et al. ; Archives of Environmental Health、Vol. 43、pp. 304 312、1988

19）松下 秀鶴、田辺 潔; 「人間環境系」研究報告集 G03P - N30、pp. 164 166、1990

20)Saffiotti、U. et al. ; J. Nat1. Cancer Inst. Vol. 49(4)、pp. 1199 1204、1972

21)石西 伸ら; 大気污染研究、Vol. 10(6)、pp. 770 777、1976

22) Horikawa 、K. et al. ; Carcinogenesis、Vol. 12(6)、pp. 1003 1007、1971

23) 安藤 満、田村憲治; 大気污染学会誌、Vol. 23(6)、pp. 342 348、1988 